\title{
Água salina e biofertilizante bovino na produção de frutos e alocação de biomassa em noni (Morinda citrifolia L.)
}

\author{
SOUTO, A.G.L.."; CAVALCANTE, L.F.2; DINIZ, B.L.M.T.2; MESQUITA, F.O. ${ }^{*} ;$ NASCIMENTO, J.A.M.4; LIMA \\ NETO, A.J. ${ }^{5}$ \\ 'UFPB/Mestrando do Programa de Pós-Graduação em Ciência do Solo, Areia, PB. ${ }^{2} P V N S / C A P E S / C C T A /$ \\ UFCG;pesquisador do INCTSal;; UFPB/CCHSA. 'UFERSA/Programa de Pós-Graduação em Manejo de Solo e \\ Água, Mossoró-RN. ${ }^{4}$ UFPB/Doutorado em Agronomia pelo departamento de Fitotecnia. ${ }^{5}$ Departamnto de Solos \\ e Adubos, Universidade Estadual de São Paulo, Jaboticabal, SP. *gusluso@hotmail.com
}

\begin{abstract}
RESUMO: Têm sido evidenciado que os compostos orgânicos exercem ação mitigadora dos efeitos tóxicos dos sais às plantas, promovendo maior crescimento e desenvolvimento em solos com excesso de sais. Nessa direção, um experimento foi desenvolvido para avaliar os efeitos do biofertilizante bovino na produção de frutos e alocação de biomassa pelos diversos órgãos de plantas de noni, irrigadas com águas salinas. Os tratamentos foram distribuídos em blocos ao acaso, com quatro repetições e duas plantas por parcela, adotando o arranjo fatorial $5 \times 2$, correspondente a salinidade das águas de irrigação de 0,$5 ; 1,5 ; 3,0 ; 4,5 ; 6,0 \mathrm{dS} \mathrm{m}^{-1}$, em substratos sem e com biofertilizante bovino, aplicado uma única vez, em volume correspondente a $10 \%$ do volume do substrato, um dia antes da instalação do experimento. As variáveis avaliadas foram: salinidade do solo, expressa pela condutividade elétrica do extrato de saturação do solo; número de frutos; massa média de fruto; produção de frutos por planta; e alocação de biomassa pelas raízes, caules, folhas e frutos. O aumento da salinidade da água de irrigação elevou o caráter salino do solo desde "não salino" para "fortemente salino" e, inibiu a produção de frutos e a acumulação de biomassa seca das plantas de noni em geral, mas, com maior intensidade nos tratamentos sem o insumo orgânico. $O$ biofertilizante estimula o crescimento e a produção de plantas de noni cultivadas sob irrigação com águas de alta salinidade.
\end{abstract}

Palavras-chave: Morinda citrifolia, esterco bovino líquido, salinidade.

\begin{abstract}
Saline water and bovine biofertilizer on yield and biomass allocation in noni plants (Morinda citrifolia L.). Organic compounds have shown to exercise a mitigating action on salts in plants and they promote growth and development in salt stress environments. In this sense, an experiment was carried out in order to evaluate the effects of saline water irrigation and bovine biofertilizer on yield and biomass allocation by the various organs of noni plants. Treatments were arranged in a randomized block design with four replications and two plants per plot using the $5 \times 2$ factorial design, which correspond to the salinity levels of irrigation water of $0.5,1.5,3.0,4.5$ and $6.0 \mathrm{dS} \mathrm{m}^{-1}$ in substrates with and without bovine biofertilizer, applied to the soil once, in the volume corresponding to $10 \%$ of the volume of the substrate one day before the implementation of the experiment. The variables evaluated were soil salinity, expressed as electrical conductivity of the soil saturation extract, fruit number, fruit weight and fruit yield per plant, and biomass allocation by roots, stems, leaves and fruit. The increasing salinity of the water for irrigation increased the saline character of the soil from non-saline to saline soil and inhibited the production and accumulation of dry biomass in noni plants in general but with more intensity in the plants of the treatments without bovine biofertilizer applied to the soil in liquid form. The biofertilizer stimulates the growth and production of noni plants grown under irrigation with high salinity water.
\end{abstract}

Keywords: Morinda citrifolia, liquid cattle manure, salinity.

\section{INTRODUÇÃO}

O noni (Morinda citrifolia) é uma planta exótica, recentemente introduzida no Brasil como cultura de exploração comercial (Silva, 2010). É utilizada na medicina tradicional da Polinésia há 
milênios, no combate a várias doenças, incluindo diabetes, pressão alta e câncer (Chan-Blanco et al., 2006; Bui et al., 2006). Praticamente todas as partes da planta são utilizadas, tais como a raiz, o caule, as folhas e principalmente o fruto (Bui et al., 2006), de onde é extraído o suco, rico em componentes fenólicos, flavonoides, vitamina $\mathrm{C}$ e compostos antioxidantes (Dussossoy et al., 2011).

Quanto às exigências edáficas, principalmente de fertilidade, é uma planta de fácil adaptação, crescendo e produzindo satisfatoriamente em solos arenosos, pouco profundos e até rochosos. Conforme relatado por Nelson \& Elevitch (2006), é uma cultura tolerante ao estresse salino, entretanto, altas concentrações de sais presentes na água de irrigação prejudicam seu crescimento e desenvolvimento (Nunes et al., 2009; Nivas et al., 2011).

Nas regiões áridas e semiáridas do Nordeste brasileiro, onde predominam baixos índices pluviométricos e irregularidade das chuvas, o conteúdo de sais nas águas é aumentado durante o período da estiagem (Cavalcante et al., 2008), resultando em mais uma adversidade às plantas. Diante da baixa oferta de água de boa qualidade para irrigação, a adoção de pesquisas que viabilizem o uso de águas salinas na exploração de plantas alimentícias e não alimentícias deve ser estimulada (Paulus et al., 2010; Santos et al., 2013).

$\mathrm{Na}$ literatura, são frequentes estudos utilizando compostos orgânicos na melhoria da fertilidade do solo (Araújo et al., 2007; Pan et al., 2009; Diniz et al., 2011). Há também, em menor proporção, pesquisas enfatizando a ação atenuadora dos compostos orgânicos, dentre eles, o biofertilizante bovino (esterco bovino líquido fermentado), sobre o efeito dos sais às plantas, como registrado por Cavalcante et al. (2010a), em goiabeira 'Paluma' (Psidium guajava), Campos et al. (2011), em maracujazeiro amarelo (Passiflora edulis) e Nunes et al. (2012), em plantas de nim (Azadirachta indica). Para Kulikova et al. (2005), as substâncias húmicas também contidas no biofertilizante bovino, contribuem para a diminuição dos efeitos tóxicos de alguns elementos, como $\mathrm{Na}^{+}$ e $\mathrm{Cl}$, às plantas glicófitas em geral.

A utilização de biofertilizante bovino, em áreas com escassez de água de boa qualidade para irrigação, pode se tornar uma alternativa viável para reduzir as perdas de produção provocadas pela utilização de águas salinas, principalmente em áreas de agricultura familiar. Diante do exposto, objetivou-se com este trabalho, avaliar a produção de frutos e o acúmulo de biomassa em plantas de noni em solo tratado com biofertilizante bovino sob irrigação com águas salinas.

\section{MATERIAL E MÉTODOS}

O experimento foi desenvolvido durante o período de julho de 2010 a junho de 2011, em ambiente telado do Centro de Ciências Agrárias da Universidade Federal da Paraíba, Areia, PB. O município possui clima quente e úmido, classificado segundo Koeppen como As', com pluviosidade média histórica de $1200 \mathrm{~mm}$ anuais (BRASIL, 1972). No local do experimento a temperatura média do ar é próxima de $23^{\circ} \mathrm{C}$, com valor mais elevado no mês de fevereiro $\left(25,7^{\circ} \mathrm{C}\right)$ e mais baixo no mês de julho $\left(21,6^{\circ} \mathrm{C}\right)$, umidade relativa do ar de $72 \%$.

O delineamento utilizado foi em blocos ao acaso, com quatro repetições e duas plantas por parcela, usando o esquema fatorial $5 \times 2$, referente a cinco níveis de condutividade elétrica da água de irrigação $\left(0,5 ; 1,5 ; 3,0 ; 4,5\right.$ e 6,0 dS m$~_{-1}{ }^{-1}$, em substrato sem e com biofertilizante bovino fermentado.

Como substrato foram utilizados $15 \mathrm{~L}$ de um LATOSSOLO VERMELHO AMARELO distrófico (EMBRAPA, 2013), coletado na camada $0-20 \mathrm{~cm}$, acondicionados em vasos plásticos com capacidade para $20 \mathrm{~L}$. Antes do acondicionamento do solo, foi colocada uma camada de brita grossa $(20 \mathrm{~mm})$ sob uma camada de areia lavada $(1,0 \mathrm{~mm})$ na base inferior de cada vaso, ambas com espessura de 2 $\mathrm{cm}$, para evitar perdas de substrato. As características químicas de fertilidade (EMBRAPA, 2011), salinidade (Richards, 1954) e físicas (EMBRAPA, 2011) analisadas estão indicadas na Tabela 1.

As diferentes condutividades elétricas da água de irrigação foram obtidas pela diluição de água fortemente salina (CEa $\left.=7,36 \mathrm{dS} \mathrm{m}^{-1}\right)$ com água não salina $\left(0,5 \mathrm{dS} \mathrm{m}^{-1}\right)$, cujas composições estão indicadas na Tabela 2 (Richards, 1954). O biofertilizante bovino foi preparado a partir da fermentação metanogênica anaeróbica de uma mistura de volumes iguais de esterco bovino fresco e água não salina e não clorada, em biodigestor, durante 30 dias, conforme recomendação de Silva et al. (2007). O biofertilizante, depois de fermentado, foi diluído em água na proporção de 1:1, e, fornecido em volume equivalente a $10 \%$ do volume do substrato, isto é, 1,5 L por unidade experimental, um dia antes da semeadura. Por ser aplicado na forma líquida, o insumo orgânico foi analisado utilizando a metodologia de água para irrigação (Tabela 3), proposta por Richards (1954).

Durante os primeiros 90 dias após a emergência (DAE) das plântulas normais, a irrigação foi feita manualmente, baseada no método da pesagem, pelo qual foi fornecido a cada vaso, o volume de água evapotranspirado no intervalo de 24 horas, de modo a elevar a umidade do solo ao nível da capacidade de campo. A partir dos $90 \mathrm{DAE}$, semanalmente, efetuou-se uma lavagem do solo com cada respectiva água de irrigação, conforme

Rev. Bras. PI. Med., Campinas, v.17, n.2, p.340-349, 2015. 
TABELA 1.Características químicas e físicas do solo quanto à fertilidade e salinidade. Areia (PB), 2011.

\begin{tabular}{|c|c|c|c|c|c|}
\hline Fertilidade & & Salinidade & & Atributos físicos & \\
\hline $\mathrm{pH}$ em água $(1: 2,5)$ & 5,07 & $\mathrm{Ph}$ & 6,09 & Dens. do solo $\left(\mathrm{g} \mathrm{cm}^{-3}\right)$ & 1,24 \\
\hline$P\left(\mathrm{mg} \mathrm{dm}^{-3}\right)$ & 1,78 & $\mathrm{Ca}^{2+}\left(\mathrm{mmol}_{\mathrm{c}} \mathrm{L}^{-1}\right)$ & 0,90 & Dens. de partícula $\left(\mathrm{g} \mathrm{cm}^{-3}\right)$ & 2,78 \\
\hline $\mathrm{K}\left(\mathrm{cmol}_{\mathrm{c}} \mathrm{dm}^{-3}\right)$ & 0,11 & $\mathrm{Mg}^{2+}\left(\mathrm{mmol}_{\mathrm{c}} \mathrm{L}^{-1}\right)$ & 0,70 & Porosidade total $\left(\mathrm{m}^{3} \mathrm{~m}^{-3}\right)$ & 0,54 \\
\hline $\mathrm{Ca}^{2+}\left(\mathrm{cmol}_{\mathrm{c}} \mathrm{dm}^{-3}\right)$ & 0,35 & $\mathrm{~K}^{+}\left(\mathrm{mmol}_{\mathrm{c}} \mathrm{L}^{-1}\right)$ & 0,11 & Areia $\left(\mathrm{g} \mathrm{kg}^{-1}\right)$ & 557 \\
\hline $\mathrm{Mg}^{2+}\left(\mathrm{cmol}_{\mathrm{c}} \mathrm{dm}^{-3}\right)$ & 0,30 & $\mathrm{Na}^{+}\left(\mathrm{mmol}_{\mathrm{c}} \mathrm{L}^{-1}\right)$ & 1,05 & Silte $\left(\mathrm{g} \mathrm{kg}^{-1}\right)$ & 63 \\
\hline $\mathrm{Na}^{+}\left(\mathrm{cmol}_{\mathrm{c}} \mathrm{dm}^{-3}\right)$ & 0,11 & $\mathrm{Cl}\left(\mathrm{mmol}_{\mathrm{c}} \mathrm{L}^{-1}\right)$ & 1,50 & Argila $\left(\mathrm{g} \mathrm{kg}^{-1}\right)$ & 380 \\
\hline $\mathrm{SB}\left(\mathrm{cmol}_{\mathrm{c}} \mathrm{dm}^{-3}\right)$ & 0,87 & $\mathrm{CO}_{3}^{2-}\left(\mathrm{mmol}_{\mathrm{c}} \mathrm{L}^{-1}\right)$ & - & Ada $\left(\mathrm{g} \mathrm{kg}^{-1}\right)$ & 26 \\
\hline $\mathrm{Al}^{3+}\left(\mathrm{cmol}_{\mathrm{c}} \mathrm{dm}^{-3}\right)$ & 0,90 & $\mathrm{HCO}_{3}^{-}\left(\mathrm{mmol}_{\mathrm{c}} \mathrm{L}^{-1}\right)$ & 1,13 & Grau de floculação (\%) & 93,3 \\
\hline $\mathrm{H}^{+}+\mathrm{Al}^{3+}\left(\mathrm{cmol}_{\mathrm{c}} \mathrm{dm}^{-3}\right)$ & 5,70 & $\mathrm{SO}_{4}^{2-}\left(\mathrm{mmol}_{\mathrm{c}} \mathrm{L}^{-1}\right)$ & 0,25 & Índice de dispersão (\%) & 6,8 \\
\hline CTC $\left(\mathrm{cmol}_{\mathrm{c}} \mathrm{dm}^{-3}\right)$ & 6,57 & CEes (dS m-1) & 0,27 & Ucc $\left(\mathrm{g} \mathrm{kg}^{-1}\right)$ & 12,8 \\
\hline $\mathrm{V}(\%)$ & 13,24 & $\operatorname{RAS}\left(\mathrm{mmol} \mathrm{L}^{-1}\right)^{0,5}$ & 1,17 & Upmp $\left(\mathrm{g} \mathrm{kg}^{-1}\right)$ & 4,5 \\
\hline $\mathrm{MO}\left(\mathrm{g} \mathrm{dm}^{-3}\right)$ & 18,25 & PST (\%) & 1,67 & Água disponível ( $\left.\mathrm{g} \mathrm{kg}^{-1}\right)$ & 8,3 \\
\hline
\end{tabular}

$\mathrm{SB}=$ soma de bases $\left(\mathrm{Na}^{+}+\mathrm{K}^{+}+\mathrm{Ca}^{2+}+\mathrm{Mg}^{2+}\right)$; CTC = Capacidade de troca catiônica [SB $\left.+\left(\mathrm{H}^{+}+\mathrm{Al}^{3+}\right)\right]$; $\mathrm{V}=$ Valor de saturação por bases $\left(100^{*} \mathrm{SB} / \mathrm{CTC}\right) ; \mathrm{RAS}=$ Razão de adsorção de sódio $\left\{\mathrm{Na}^{+} /\left[\left(\mathrm{Ca}^{2+}+\mathrm{Mg}^{2+}\right) / 2\right]^{1 / 2}\right\} ; \mathrm{MO}=$ matéria orgânica; Ucce Upmp = Umidade ao nível de capacidade de campo e de ponto de murchamento permanente do solo; PST = Percentagem de sódio trocável $\left(100^{\star} \mathrm{Na} /\right.$ CTC); CEes $=$ condutividade elétrica do extrato de saturação.

TABELA 2. Caracterização química das águas utilizadas para preparação das águas salinas utilizadas na irrigação das plantas. Areia (PB), 2011.

\begin{tabular}{|c|c|c|c|c|c|c|c|c|c|c|c|}
\hline Componentes & $\mathrm{CE}_{\mathrm{a}}$ & $\mathrm{Ca}^{2+}$ & $\mathrm{Mg}^{2+}$ & $\mathrm{Na}^{+}$ & $\mathrm{K}^{+}$ & $\mathrm{SO}_{4}^{-2}$ & $\mathrm{CO}_{3}^{-2}$ & $\mathrm{HCO}_{3}{ }^{-2}$ & $\mathrm{Cl}^{-}$ & RAS & Clas. \\
\hline \multicolumn{12}{|c|}{$d S m^{-1}$} \\
\hline Água não salina & 0,50 & 1,23 & 0,75 & 2,64 & 0,13 & 0,82 & - & 0,32 & 3,84 & 2,65 & $\mathrm{C}_{1} \mathrm{~S}_{1}$ \\
\hline Água salina & 7,36 & 4,80 & 8,90 & 61,96 & 0,43 & 0,26 & 0,10 & 3,20 & 69,06 & 0,80 & $\mathrm{C}_{4} \mathrm{~S}_{1}$ \\
\hline
\end{tabular}

TABELA 3. Caracterização química do biofertilizante bovino. Areia (PB), 2011.

\begin{tabular}{|c|c|c|c|c|c|c|}
\hline $\mathrm{CE}_{\mathrm{b}}$ & $\mathrm{Ca}^{2+}$ & $\mathrm{Mg}^{2+}$ & $\mathrm{Na}^{+}$ & $\mathrm{K}^{+}$ & RAS & Clas. \\
\hline$d S \mathrm{~m}^{-1}$ & - & $\mathrm{nmol}_{\mathrm{c}}$ & 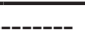 & & --mmol L0,5--- & \\
\hline 3,11 & 9,38 & 6,87 & 4,16 & 10,57 & 1,46 & $\mathrm{C}_{4} \mathrm{~S}_{1}$ \\
\hline
\end{tabular}

$\mathrm{CEb}=$ Condutividade elétrica do biofertilizante; RAS-Razão de adsorção de sódio= $\mathrm{Na}^{+} /\left[\left(\mathrm{Ca}^{2+}+\mathrm{Mg}^{2+}\right) / 2\right]^{0,5}$; Clas= Classificação

Ayers \& Westcot (1999). Durante esse período, diariamente, as plantas foram irrigadas com cada tipo de água e o volume aplicado foi registrado. No dia da lavagem, aplicou-se paulatinamente, com auxílio de proveta graduada, o volume de cada tipo de água até o início da drenagem do solo; em seguida adicionou-se mais $10 \%$ do total já aplicado para proceder à lavagem e a lixiviação dos sais de cada vaso (Cavalcante et al., 2010b). Ao final de cada lavagem, quando a drenagem cessou, registraram-se os volumes lixiviados e adicionaramse os volumes aplicados diariamente para o cálculo do consumo hídrico das plantas, em cada intervalo semanal, pela expressão:

$$
\mathrm{Ch}=10^{*}(\mathrm{Vap}-\mathrm{Vd}) / \mathrm{A}^{*} \mathrm{~T}
$$

Em que: $\mathrm{Ch}=$ Consumo hídrico $\left(\mathrm{mm}\right.$ dia-1 $\left.^{-1}\right) ; \mathrm{Vap}=$ Volume aplicado $\left(\mathrm{cm}^{3}\right) ; \mathrm{Vd}=$ Volume drenado $\left(\mathrm{cm}^{3}\right)$; $\mathrm{A}=$ Área do vaso $\left(\mathrm{cm}^{2}\right) ; \mathrm{T}$ = Período entre lavagens do solo (7 dias).

Ao final do experimento, efetuou-se a soma do consumo hídrico total $(\mathrm{mm})$ e, dividiu-se pelo período de dias após a emergência, para obtenção dos consumos diários pelas plantas ( $\left.\mathrm{mm} \mathrm{dia}^{-1}\right)$, em função de cada nível de salinidade das águas.

Ao final do experimento (330 DAE), foram avaliados: condutividade elétrica do extrato de saturação do solo (Richards, 1954), número de frutos por planta, massa média dos frutos (MMF), produção total e matéria seca total (MST), através do somatório das matérias secas da parte aérea (caule, folhas, ramos produtivos e frutos) e da raiz, após secagem em estufa com ventilação forçada a $65^{\circ} \mathrm{C}$, por 72 horas. A alocação de biomassa dos diferentes órgãos (raiz, caule, folha e frutos) foi calculada seguindo a metodologia empregada por Benincasa (2003):

Alocação de biomassa órgão = (BMSórgão / BMStotal) $\times 100$

BMSórgão = biomassa seca do órgão (raiz, caule, folha e fruto);

BMStotal = biomassa seca total . 
Os dados foram submetidos à análise de variância, pelo teste " $F$ ", enquanto as médias referentes ao fornecimento de biofertilizante foram comparadas pelo teste de Tukey a $5 \%$ de probabilidade e as referentes aos níveis de salinidade da água, por análise de regressão (Ferreira, 2011). Para o processamento dos dados, foi utilizado o software estatístico SISVAR.

\section{RESULTADOS E DISCUSSÃO}

À exceção da alocação de biomassa seca pelas raízes e folhas das plantas, que não responderam a quaisquer das fontes de variação, todas as variáveis analisadas foram influenciadas significativamente pela interação salinidade da água de irrigação $\times$ biofertilizante bovino (Tabela 4). Diferentemente, Campos et al. (2009) e Diniz et al. (2011) constataram que o biofertilizante bovino estimulou a produção de fitomassa das raízes e folhas em plantas de mamoneira e maracujazeiro amarelo, respectivamente.

O incremento de sais na água de irrigação elevou a condutividade elétrica do extrato de saturação do solo (CEes) de forma quadrática, mas, nos tratamentos com a presença de biofertilizante, os valores foram expressivamente maiores (Figura 1). Observa-se valores máximos de 21,53 e 26,63 dS $\mathrm{m}^{-1}$ na condutividade elétrica do solo, obtidos nas águas de irrigação com condutividade elétrica de 3,68 e 4,78 dS $\mathrm{m}^{-1}$ no solo sem e com biofertilizante, respectivamente (Figura 1). A superioridade de valores, apresentada nos tratamentos com insumo orgânico, possivelmente é resposta ao incremento de sais pelo respectivo insumo que apresentou 3,11 dS $\mathrm{m}^{-1}$, após a fermentação (Tabela 3 ).

Ao considerar que o solo, antes da aplicação dos tratamentos, possuía CEes de 0,17 dS $\mathrm{m}^{-1}$, constata-se expressiva elevação do caráter de não salino para até muito fortemente salino $\left(\right.$ CEes $=21,52$ e 26,63 dS $\left.\mathrm{m}^{-1}\right)$, no substrato sem e com biofertilizante, respectivamente. Esse nível de condutividade elétrica do solo é considerado restritivo ao crescimento e desenvolvimento da grande maioria das plantas cultivadas (Ayers \& Wescot, 1999). Percebe-se, ainda, declínio de valores de CEes após os valores máximos (Figura 1). Isso se deve ao fato de que, em solos com excesso de sais, há aumento da permeabilidade, o que facilita a remoção dos sais do perfil pela água de irrigação diária e aplicação da lâmina de lixiviação (Santos et al., 2010).

Comparativamente, os resultados apresentados diferem dos obtidos por Cavalcante et al. (2010a), que não constataram variação significativa da salinidade do solo, em função da presença e ausência de biofertilizante, quando irrigados com águas salinas. No entanto, de forma geral, também houve incremento na salinidade do solo de 0,22 dS $\mathrm{m}^{-1}$ para até 7,99 $\mathrm{dS} \mathrm{m}^{-1}$.

O número de frutos por planta foi significativamente reduzido pelo incremento de sais da água de irrigação (Figura 2). Inicialmente, ele foi superior nas plantas do solo sem biofertilizante irrigadas com águas de até $3 \mathrm{dS} \mathrm{m}^{-1}$; a partir desse nível salino, o número de frutos de noni foi superior nas plantas tratadas com o insumo orgânico.

Nos tratamentos com biofertilizante bovino, o número de frutos colhidos foi reduzido, em média, de 8,2 , no nível salino $0,5 \mathrm{dS} \mathrm{m}^{-1}$ para até 1,6 frutos no nível $6,0 \mathrm{dS} \mathrm{m}^{-1}$, causando uma queda de $81,3 \%$ no número de frutos. Apesar do declínio, a adição do biofertilizante possibilitou o uso de água com salinidade de até 2,13 dS $\mathrm{m}^{-1}$, que já oferece riscos

TABELA 4. Resumo da análise de variância, pelo quadrado médio, referente aos valores condutividade elétrica do extrato de saturação do solo (CEes), número de frutos (NF), massa média dos frutos (MMF), produção por planta (PP), matéria seca total (MST), alocação de biomassa de raiz (ABR), alocação de biomassa no caule $(A B C)$, alocação de biomassa nas folhas (ABF) e alocação de biomassa nos frutos de plantas de noni (Morinda citrifolia L.) cultivadas em substrato sem e com biofertilizante bovino e irrigadas com água salina. Areia (PB), 2011.

\begin{tabular}{|c|c|c|c|c|c|c|c|c|c|c|}
\hline \multirow{2}{*}{ FV } & \multirow{2}{*}{ GL } & \multicolumn{9}{|c|}{ Quadrado Médio } \\
\hline & & CEes & NF & MMF & PP & MST & $A B R$ & $A B C$ & $\mathrm{ABF}$ & ABFR \\
\hline Blocos & 3 & $1,49^{\text {ns }}$ & $2,80^{\text {ns }}$ & $13,71^{\text {ns }}$ & $3485,61^{\text {ns }}$ & $536,02^{\mathrm{ns}}$ & $150,70^{\text {ns }}$ & $35,35^{\text {ns }}$ & $224,93^{\mathrm{ns}}$ & $20,65^{\text {ns }}$ \\
\hline Bio & 1 & $65,02^{* *}$ & $4,90^{\mathrm{ns}}$ & $5,69^{n s}$ & $23816,35 *$ & $664,22^{\mathrm{ns}}$ & $77,64^{\text {ns }}$ & $271,70^{* \prime}$ & $3,34^{\text {ns }}$ & $26,56^{\text {ns }}$ \\
\hline Água & 4 & $429,25 *$ & $212,41^{*}$ & $418,91^{* *}$ & $55831,10^{* *}$ & 70012,28 & $232,69^{\text {ns }}$ & $89,59^{*}$ & $383,14^{\text {ns }}$ & $250,98 *$ \\
\hline$B \times A$ & 4 & $54,15^{*}$ & 23,46 & $75,31^{* *}$ & $28346,82^{*}$ & $7296,91^{* *}$ & $169,02^{\text {ns }}$ & $112,28 *$ & $35,93^{\text {ns }}$ & $119,80 *$ \\
\hline Resíduo & 27 & 6,93 & 5,61 & 8,06 & 1042,39 & 1042,29 & 297,47 & 22,56 & 267,40 & 21,17 \\
\hline CV. (\%) & & 16,59 & 27,24 & 30,44 & 37,45 & 21,08 & 54,15 & 29,57 & 42,48 & 59,32 \\
\hline
\end{tabular}

** - efeito significativo pelo teste $\mathrm{F}$ ao nível de $1 \%$ de probabilidade; * - efeito significativo pelo teste $\mathrm{F}$ ao nível de $5 \%$ de probabilidade; ns - efeito não significativo pelo teste $\mathrm{F}$. 


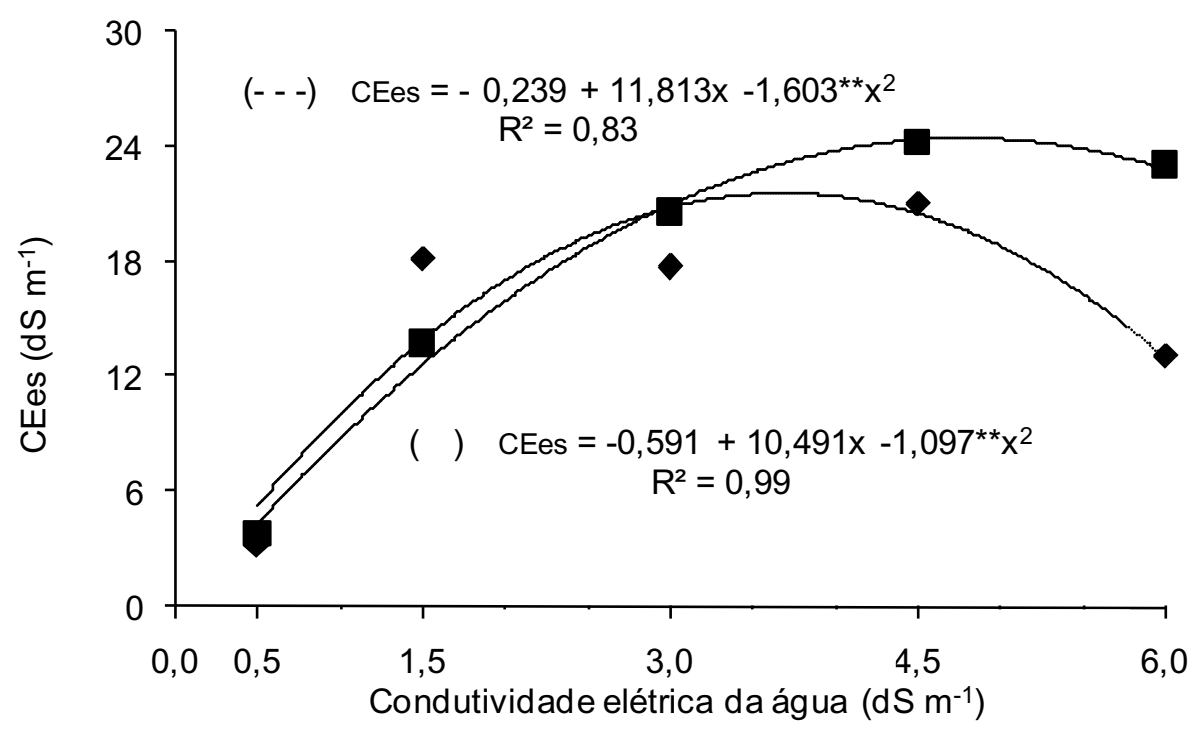

FIGURA 1. Condutividade elétrica do extrato de saturação (CEes) do substrato sem (- - -) e com (-) biofertilizante bovino e irrigado com água salina. Areia (PB), 2011.

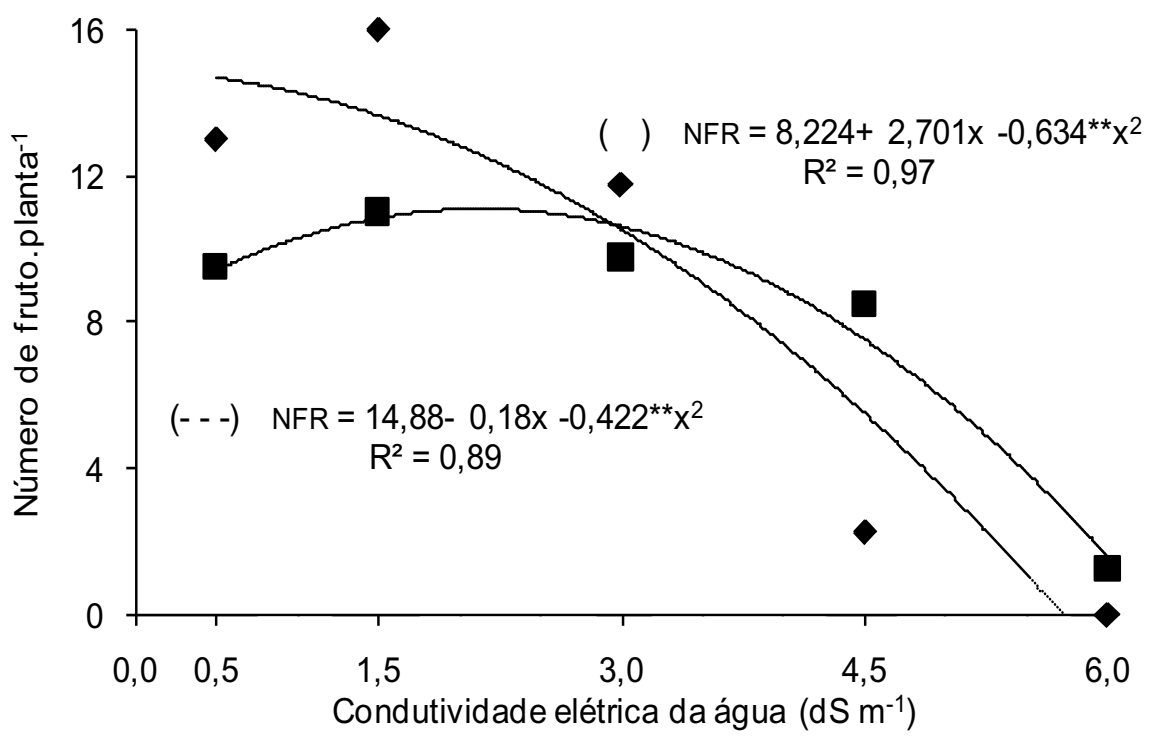

FIGURA 2. Número de frutos por planta de noni em solo sem (- - -) e com (-) biofertilizante bovino e irrigação com água salina. Areia (PB), 2011.

à grande maioria das plantas cultivadas (Ayers \& Westcot, 1999), inclusive ao noni (Nivas et al., 2011).

Ao considerar que, nas plantas cultivadas no solo sem biofertilizante, a irrigação com água de salinidade a partir de $0,5 \mathrm{dS} \mathrm{m}^{-1}$ já inibiu a produção de frutos, constata-se que o insumo orgânico atenuou os efeitos negativos do excesso de sais ao noni. Esses resultados, em parte, podem ser atribuídos ao fornecimento de nutrientes e aumento da atividade biológica do solo (Cavalcante et al., 2010a; Dias et al., 2011). Por outro lado, de acordo com Khaled \& Fawy (2011), as substâncias húmicas contidas em compostos orgânicos, como os ácidos húmicos, além de melhorar a estrutura do solo, aumentam a divisão celular e a permeabilidade das membranas celulares, proporcionando maior absorção de água e nutrientes em plantas submetidas a estresse salino, e, consequentemente, maior produção de frutos.

O incremento de sais na água de irrigação, assim como para o número de frutos, resultou em decréscimo significativo da massa média dos frutos de noni (Figura 3). No entanto, nas plantas cultivadas em solo com biofertilizante, os valores foram superiores aos verificados nas plantas onde o solo não foi tratado com o insumo orgânico. Essa tendência já foi observada por Blanco \& Folegatti (2008) para massa média de frutos de tomate (Lycopersicum esculentum) irrigado com água salina. Esse declínio, na maioria das plantas, é devido ao efeito tóxico dos íons $\mathrm{Na}^{+}$e $\mathrm{Cl}$-em excesso, que podem provocar redução da absorção de água e nutrientes e desequilíbrio no balanço catiônico 
e no metabolismo vegetal, ocasionando perdas no crescimento e na produção (Marschner, 2005; Munns \& Tester, 2008; Nivas et al., 2011).

No solo com o insumo orgânico, o aumento da salinidade da água de 0,5 para até 2,18 dS $\mathrm{m}^{-1}$ estimulou o aumento da massa média dos frutos até o valor máximo de 13,42 g (Figura 3). A irrigação com águas de condutividade elétrica superior a 2,18 dS $\mathrm{m}^{-1}$ induziu toxicidade às plantas de noni, com perdas totais nas plantas irrigadas com águas de salinidade superior a 5,0 dS m-1. Como para o número de frutos por planta, constata-se também que, apesar de o biofertilizante não eliminar o efeito negativo dos sais ao noni, reduz paulatinamente esses efeitos, como verificado por Freire et al. (2010) na massa média de frutos de maracujazeiro amarelo, irrigado com águas de salinidade crescente. A ação mitigadora do biofertilizante à salinidade está relacionada à melhoria física do solo para dinâmica de ar e água (Mellek et al., 2010), ao aumento na população, diversidade e atividade microbiana (Vessey, 2003) e à melhoria da fertilidade do solo. Esses aspectos, conforme Asik et al. (2009), contribuem para maior absorção de água pelas plantas em meios salinos.

O aumento do teor salino da água de irrigação prejudicou a produção de frutos por planta de noni, mas, em menor intensidade no solo com o biofertilizante sob irrigação com águas de condutividade elétrica acima de 2,70 dS m-1 (Figura 4). No solo sem o insumo orgânico, a produção foi reduzida de $340 \mathrm{~g}$, nas plantas irrigadas com a água não salina $\left(0,5 \mathrm{dS} \mathrm{m}^{-1}\right)$, para valor nulo, nas irrigadas com água de condutividade elétrica a partir de 5,0
dS $\mathrm{m}^{-1}$. A salinidade do solo provoca redução das trocas gasosas, com declínio na fixação de $\mathrm{CO}_{2} \mathrm{e}$ na eficiência fotossintética e aumento do acúmulo de sais, principalmente nas folhas, com reflexos negativos no rendimento (Taiz \& Zeiger, 2013), como registrado também por Dias et al. (2011), ao irrigarem maracujazeiro amarelo com águas salinas em solo com biofertilizante bovino.

No solo com biofertilizante bovino, houve aumento da produção de frutos de noni quando as plantas foram irrigadas com águas de até 1,72 dS $\mathrm{m}^{-1}$. A partir desse valor, observou-se decréscimo com o aumento do teor salino da água de irrigação (Figura 4). Verificaram-se tendências semelhantes entre as variáveis de produção, o que significa que houve coerência entre os dados. Além disso, a produção expressa diretamente o número e massa média dos frutos.

As plantas cultivadas no solo sem o biofertilizante apresentaram perda linear de matéria seca total, ao nível de $51,1 \mathrm{~g}$ planta-1 por aumento unitário da condutividade elétrica da água (Figura $5)$. Ao relacionar os valores entre as plantas

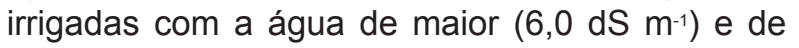

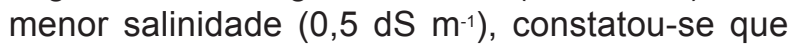
as perdas foram de $100 \%$. Apesar de também apresentar perdas de matéria seca, essas foram inferiores nas plantas do solo tratado com o insumo orgânico. O biofertilizante estimulou a produção de matéria seca total do noni, quando irrigado com água de condutividade elétrica de até 1,55 dS $\mathrm{m}^{-1}$, com valor máximo de $213 \mathrm{~g}$ planta-1 $^{-1}$ (Figura 5). Comportamento semelhante foi registrado por

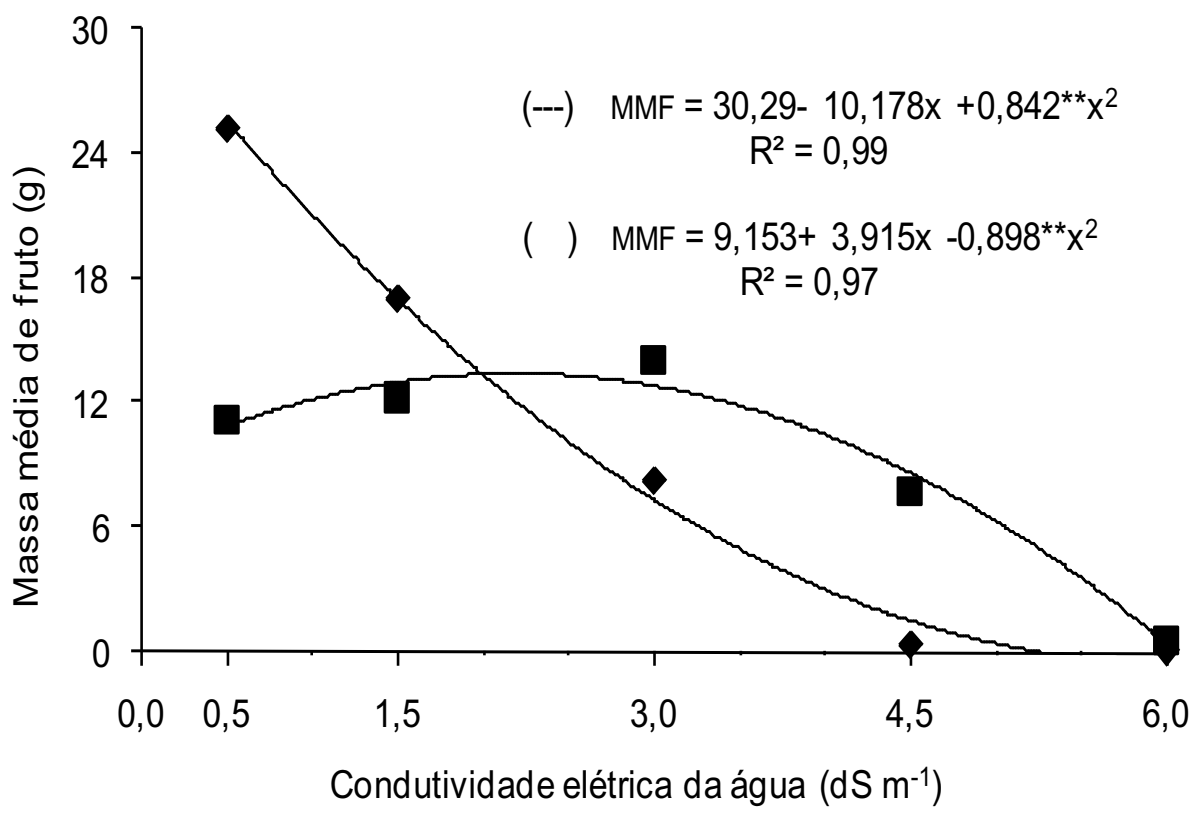

FIGURA 3. Massa média de frutos de noni em solo sem (- - -) e com (-) biofertilizante bovino e irrigação com água salina. Areia (PB), 2011.

Rev. Bras. PI. Med., Campinas, v.17, n.2, p.340-349, 2015. 


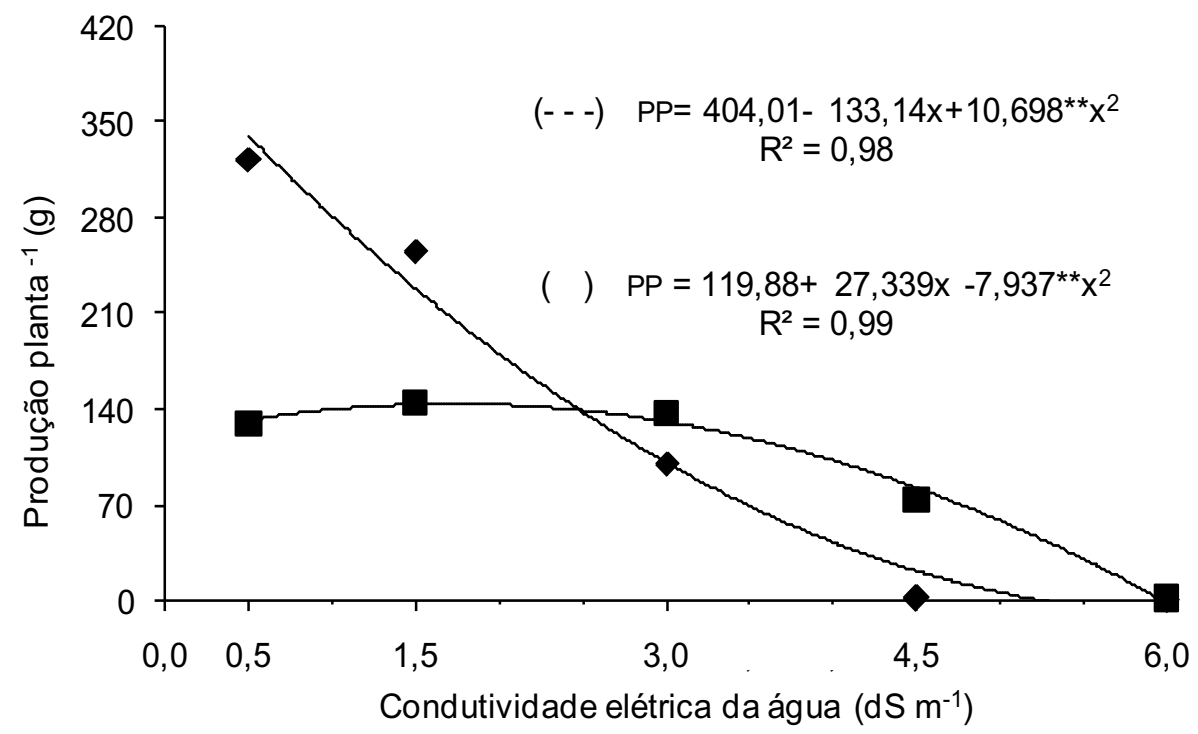

FIGURA 4. Produção por planta de noni em solo sem (- - -) e com (-) biofertilizante bovino e irrigação com água salina. Areia (PB), 2011.

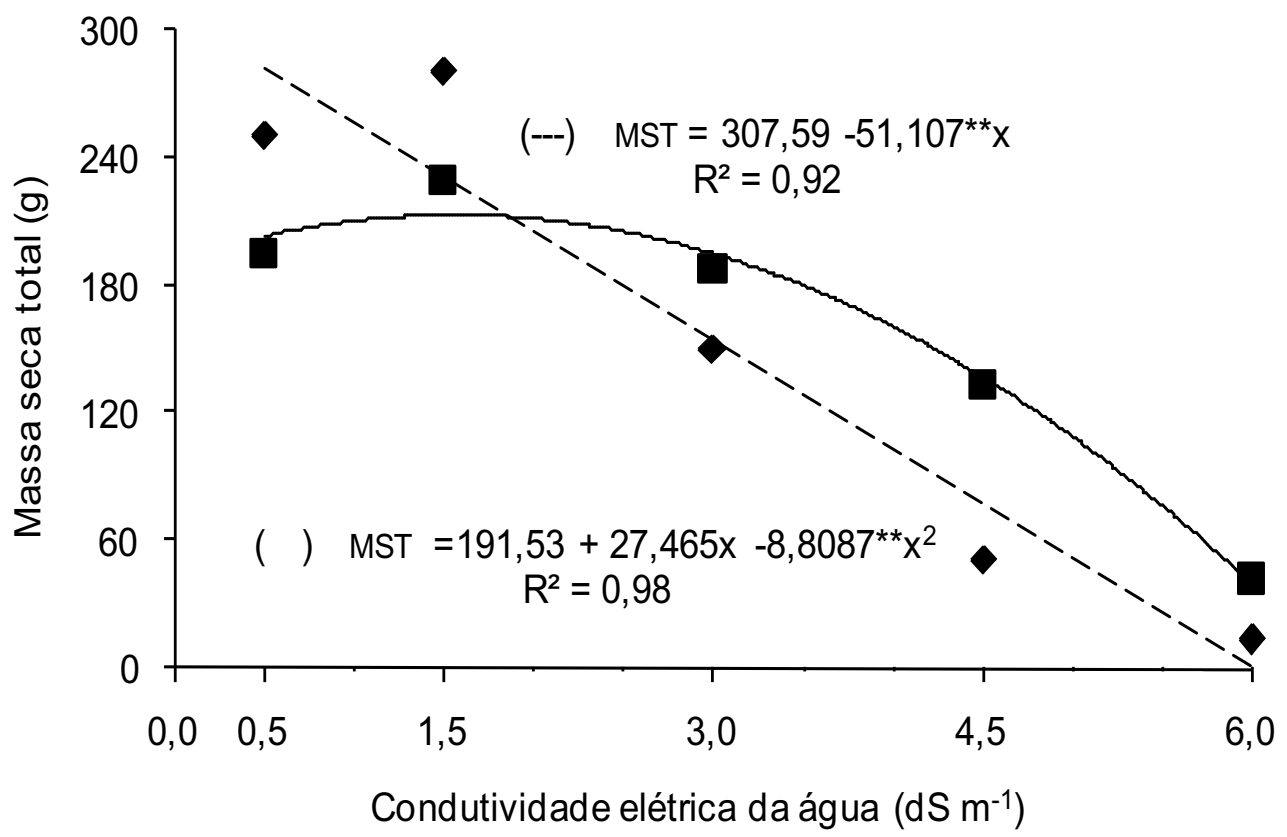

FIGURA 5. Matéria seca total de plantas de noni em solo sem (- - -) e com (-) biofertilizante bovino e irrigação com água salina. Areia (PB), 2011.

Cavalcante et al. (2010a) e Nunes et al. (2012) em plantas de goiabeira 'Paluma' e de nim (Azadirachta indica) irrigadas com águas salinas, no solo com biofertilizante bovino, respectivamente. Em ambas as situações, o excesso de sais comprometeu os processos fisiológicos e metabólicos das culturas, mas, sempre com menor intensidade nas plantas do solo com o insumo orgânico.

A alocação de biomassa pelo caule e frutos foi inibida linearmente aos níveis de 1,87 e 3,74 $\%$ por aumento unitário da salinidade das águas, no substrato sem biofertilizante (Figura 6A e 6B). Comparativamente, nos tratamentos sem o insumo orgânico percebe-se que o excesso de sais da água de irrigação comprometeu mais expressivamente a produção de matéria seca dos frutos do que do caule. Com base nesses resultados, verificou-se que o noni, assim como observado para a grande maioria das plantas glicófitas (Ayers \& Westcot, 1999; Munns \& Tester, 2008), revela-se mais susceptível à salinidade na fase reprodutiva do que na fase vegetativa. 

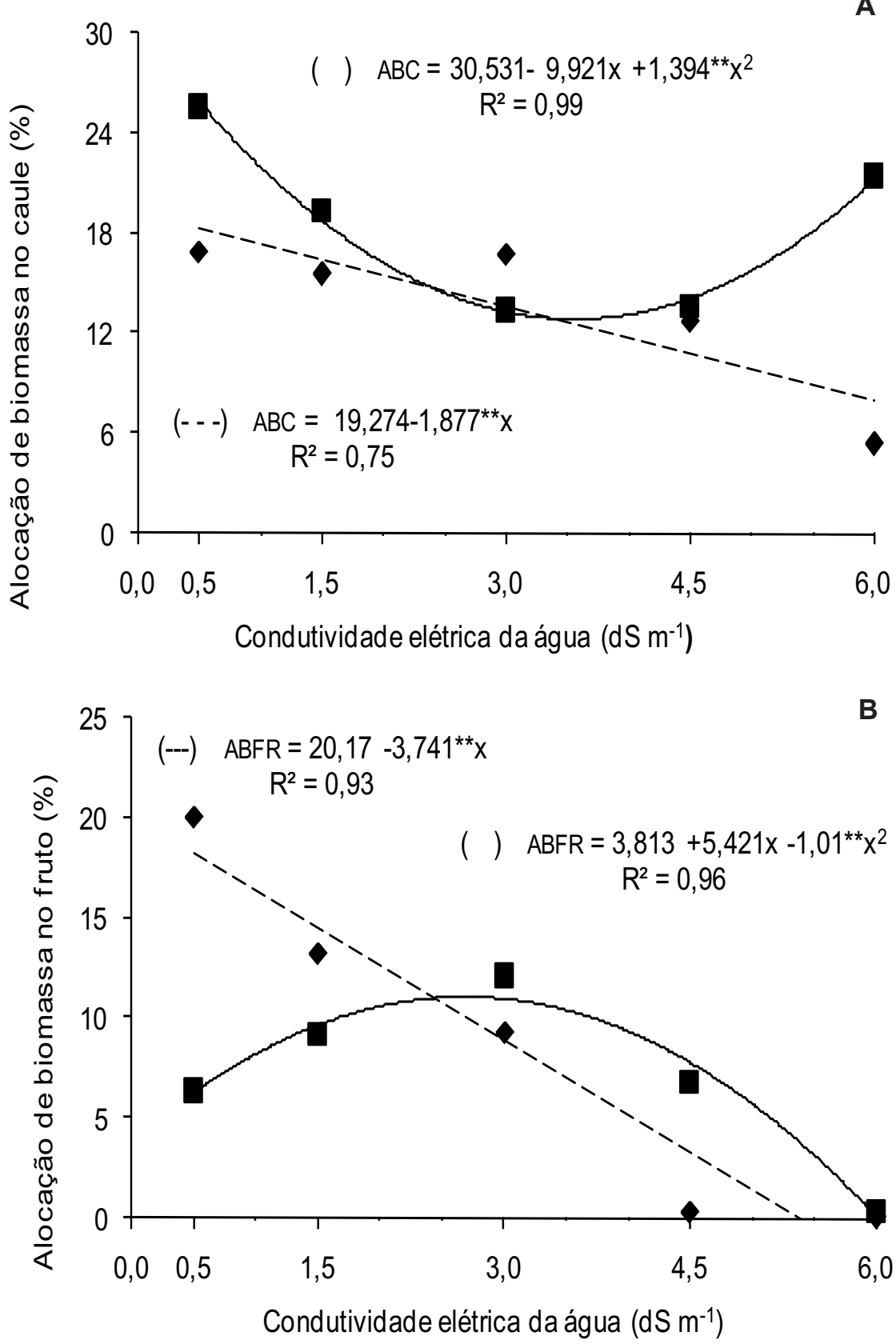

FIGURA 6. Alocação de biomassa de caule (A) e frutos (B) de plantas de noni em solo sem (- - -) e com (-) biofertilizante bovino e irrigação com água salina. Areia (PB), 2011.

Nos tratamentos com o biofertilizante bovino, a alocação de biomassa pelo caule diminuiu inicialmente com o aumento da salinidade das águas até o valor mínimo de $12,87 \%$ na condutividade de $3,55 \mathrm{dS} \mathrm{m}^{-1}$ (Figura 6A). A irrigação com águas de teor salino superior a 3,55 dS $\mathrm{m}^{-1}$ elevou a alocação de biomassa pelo caule das plantas, atingindo o valor máximo referente à água de maior índice salino. Verificou-se também que a alocação de biomassa pelos frutos de noni aumentou com a salinidade das águas até 2,68 dS m-1, expressando o valor máximo de $11,08 \%$ (Figura 6B). Nas plantas do solo com o insumo orgânico, o incremento na alocação de biomassa entre os distintos órgãos das plantas, em relação ao dos tratamentos sem biofertilizante, é resposta, dentre outros fatores, da melhoria física, química e biológica do solo, proporcionada pelo biofertilizante (Sheteawi \& Tawfik, 2007), resultando em maior produção de biomassa. Nesse contexto, Vessey (2003) relata que os biofertilizantes podem promover a proliferação de microrganismos capazes de exercer efeitos benéficos no crescimento das plantas sob estresse salino.

Rev. Bras. Pl. Med., Campinas, v.17, n.2, p.340-349, 2015. 


\section{CONCLUSÕES}

O fornecimento de biofertilizante elevou a salinidade do solo quando irrigado com águas de condutividade elétrica igual ou superior a $3 \mathrm{dS} \mathrm{m}^{-1}$.

O biofertilizante não anula, mas, inibe a ação negativa do excesso de sais da água de irrigação às plantas de noni.

O biofertilizante estimula o crescimento e produção de plantas de noni, cultivadas sob irrigação com águas de alta salinidade.

\section{AGRADECIMENTOS}

Ao Instituto Nacional de Ciência e Tecnologia em Salinidade - INCTSal e ao Nacional de Desenvolvimento Científico e Tecnológico-CNPq, pelo suporte financeiro e pela concessão da bolsa do primeiro autor.

\section{REFERÊNCIAS}

ARAÚJO, E.N. et al. Produção do pimentão adubado com esterco bovino e biofertilizante. Revista Brasileira de Engenharia Agrícola e Ambiental, v.11, n.5, p.466470, 2007.

ASIK, B.B. et al. Effects of humic substances on plant growth and mineral nutrients uptake of wheat (Triticum durum cv. Salihli) under conditions of salinity. Asian Journal of Crop Science, v.1, p.87-95, 2009.

AYERS, R.S.; WESTCOT, D.W. A qualidade da água na agricultura. Campina Grande: UFPB. 1991, 218p. Estudos FAO Irrigação e Drenagem, 29 revisado.

BENINCASA, M.M.P. Análise de crescimento de plantas: noções básicas. Jaboticabal: FUNEP, 2003. $41 \mathrm{p}$.

BLANCO, F.F.; FOLEGATTI, M.V. Doses de N e K no tomateiro sob estresse salino: III. Produção e qualidade de frutos. Revista Brasileira de Engenharia Agrícola e Ambiental, v.12, n.2, p.122-127, 2008.

BRASIL. Ministério da Agricultura. Levantamento exploratório-reconhecimento de solos do Estado da Paraíba. Rio de Janeiro: MA/COMTAP/USAID/ SUDENE, 1972. 670 p. (Boletim Técnico 15).

BUI, A.K.T.; BACIC, A.; PETTOLINO, F. Polysaccharide composition of the fruit juice of Morinda citrifolia (Noni). Phytochemistry, v.67, n1, p.1271-1275, 2006.

CAMPOS, V.B. et al. Esterco bovino líquido em luvissolo sódico: I. Resposta biométrica e produtiva do maracujazeiro amarelo. Idesia, v.29, n.2, p.59-67, 2011.

CAMPOS, V.B. et al. Crescimento inicial da mamoneira submetido à irrigação com água salina e biofertilizante bovino. Magistra, v.21, n.1, p.40-47, 2009.

CAVALCANTE, L.F. et al. Recuperação de solos afetados por sais. In: GHEYI, H.R.; DIAS, N.S.; LACERDA, C.F. (Eds). Manejo da salinidade na agricultura: estudos básicos e aplicados. Fortaleza: INCTSal. Parte V, 2010b, p.425-448.

CAVALCANTE, L.F. et al. Água salina e esterco bovino líquido na formação de mudas de goiabeira cultivar Paluma. Revista Brasileira de Fruticultura, v.32, n.1, p.251-261, 2010a.

CAVALCANTE, L.F. et al. Biomassa do maracujazeiroamarelo em solo irrigado com água salina protegido contra as perdas hídricas. Revista Verde de Agroecologia e Desenvolvimento Sustentável, v.3, n.3, p.26-34, 2008.

CHAN-BLANCO, Y. et al. The noni fruit (Morinda citrifolia L.): a review of agricultural research, nutritional and therapeutic properties. Journal of Food Composition and Analysis, v.19, p.645-654, 2006.

DIAS, T.J. et al. Produção do maracujazeiro e resistência mecânica do solo com biofertilizante sob irrigação com águas salinas, Revista Ciência Agronômica, v.42, n.3, p.644-651, 2011.

DINIZ, A.A. et al. Esterco líquido bovino e ureia no crescimento e produção de biomassa do maracujazeiro amarelo, Revista Ciência Agronômica, v.42, n.3, p.597-604, 2011.

DUSSOSSOY, E. et al. Characterization, anti-oxidative and anti-inflammatory effects of Costa Rican noni juice (Morinda citrifolia L.), Journal of Ethnopharmacology, v.133, p.108-115, 2011.

EMBRAPA-Empresa Brasileira de Pesquisa Agropecuária. Manual de análises químicas de solos, plantas e fertilizantes. Brasília: Embrapa Solos/Embrapa Informação Tecnológica, 2011. 627p.

EMBRAPA. Sistema brasileiro de classificação de solos. 3 ed. Brasília, DF: Embrapa, 2013. 353 p.

FERREIRA, D.F. Sisvar: a computer statistical analysis system. Ciência e Agrotecnologia, v.35, n.6, p.10391042, 2011.

FREIRE, J.L.O. et al. Atributos qualitativos do maracujá amarelo produzido com água salina, biofertilizante e cobertura morta no solo. Revista Brasileira de Ciências Agrárias, v.5, n.1, p.102-110, 2010.

KHALED, H.; FAWY, H.A. Effect of different levels of humic acids on the nutrient content, plant growth, and soil properties under conditions of salinity, Soil \& Water Research, v.6, n.1, p.21-29, 2011.

KULIKOVA, N.A.; STEPANOVA, E.V.; KOROLEVA, O.V. Mitigating Activity of Humic Substances: Direct Influence on Biota, p. 285-309. In: Perminova IV (Ed.). Use of humic substances to remediate polluted environments: from theory to practice, NATO Science Series IV: Earth and Environmental Series. Kluwer Academic Publishers, USA, 2005.

MARSCHNER, H. Mineral nutrition of higher plants. 2 ed. London: Academic Press, 2005, 889p.

MELLEK, J.E. et al. Dairy liquid manure and no-tillage: Physical and hydraulic properties and carbon stocks in a Cambisol of Southern Brazil. Soil Tillage Research, v.110, n.1, p.69-76, 2010.

MUNNS, R.; TESTER, M. Mechanisms of salinity tolerance. Annual Review of Plant Biology, v.59, n.1, p.651-681, 2008.

NELSON, S.C.; ELEVITCH, C.R. Noni: the complete guide for consumers and growers. Holualoa-Hawaii. Permanent Agriculture Resoucers, 2006.

NIVAS, D.; GAIKWAD, D.K.; CHAVN, P.D. Physiological responses of two Morinda Species under saline conditions. American Journal of Plant Physiology. p.1-10, 2011.

NUNES, J.C. et al. Comportamento de mudas de 
nim à salinidade da água em solo não salino com biofertilizante, Revista Brasileira de Engenharia Agrícola e Ambiental, v.16, n.11, p.1152-1158, 2012.

NUNES, J.C. et al. Formação de mudas de noni sob irrigação com águas salinas e biofertilizante bovino no solo. Engenharia Ambiental, v.6, n.2, p.451463, 2009.

PAN, G.; SMITH, P.; PAN, W. The role of soil organic matter in maintaining the productivity and yield stability of cereals in china. Agriculture, Ecosystems \& Environment, v. 129, p.344-348, 2009.

PAULUS, D. et al. Produção e indicadores fisiológicos de alface sob hidroponia com água salina. Horticultura Brasileira, v.28, n.1, p.29-35, 2010.

RICHARDS, L.A. Diagnosis and improvement of saline and alkaline soils. Washington: United States Salinity Laboratory Staff, 1954. 160p. (Agriculture, 60).

SANTOS, J.B. et al. Comportamento morfofisiológico da mamoneira BRS Energia submetida à irrigação com água salina. Revista Brasileira de Engenharia
Agrícola e Ambiental, v.17, n.2, p.145-152. 2013.

SANTOS, R.V. et al. Interações salinidade-fertilidade do solo. GHEYI. H.R. Manejo da salinidade na agricultura: Estudos básicos e aplicados. Fortaleza: INCTsal, 2010. p.221-250.

SHETEAWI, S.A.; TAWFIK, K.M. Interation effect of some biofertilizers and irrigation water regime on mung bean (Vigna radiate) grow the and yield. Applied Sciences Reseach, v.3, p.251-262, 2007.

SILVA, A.F. et al. Preparo e uso de biofertilizantes líquidos. Comunicado Técnico, Petrolina, n. 130, 4p. 2007.

SILVA, J. J. M. Adubação orgânica e mineral de noni: desempenho agronômico, nutrição da planta, qualidade de fruto e de suco. Areia: 2010. $104 \mathrm{f}$. Tese (Doutorado-Solos e nutrição de plantas) Departamento de Ciências Ambientais, Universidade Federal da Paraíba, Areia.

TAIZ, L.; ZEIGER, E. Fisiologia Vegetal. 3. ed. Porto Alegre: Artmed Editora, 2013, 954p.

VESSEY, J.K. Plant growth promoting rhizobacteria as biofertilizers. Plant and Soil, v.255, p.571-586, 2003. 